\title{
Infectious diseases in the first year of life, perinatal characteristics and childhood acute leukaemia
}

\section{N Jourdan-Da Silva', Y Perel ${ }^{2}$, F Méchinaud ${ }^{3}$, E Plouvier ${ }^{4}$, V Gandemer ${ }^{5}$, P Lutz ${ }^{6}$, JP Vannier ${ }^{7}$, JL Lamagnére ${ }^{8}$, G Margueritte', P Boutard ${ }^{10}$, A Robert '1, C Armari' ${ }^{12}$, M Munzer ${ }^{13}$, F Millot ${ }^{14}$, L de Lumley ${ }^{15}$, C Berthou $^{16}$, X Rialland ${ }^{17}$, B Pautard ${ }^{18}$, D Hémon' and J Clavel ${ }^{*, 1}$}

'Institut National de la Santé et de la Recherche Médicale, INSERM UI 70-IFR69, 94807 Villejuif, France; ${ }^{2}$ Hôpital Pellegrin, Bordeaux, France; ${ }^{3}$ Hôtel Dieu. Hôpital mère et enfant, Nantes, France; ${ }^{4}$ Hôpital Saint-Jacques, Besançon, France; ${ }^{5}$ Hôpital Sud, Rennes, France; ${ }^{6}$ Hôpital Civil, Strasbourg, France; ${ }^{7}$ Hôpital Charles Nicolle, Rouen, France; ${ }^{8} \mathrm{CHRU}$ Clocheville, Tours, France; ${ }^{9}$ Hôpital Arnaud de Villeneuve, Montpellier, France; ${ }^{10}$ Hôpital de la Côte de Nacre, Caen, France; "'Hôpital d'Enfants, Toulouse, France; ${ }^{12}$ Hôpital de la Tronche, Grenoble, France; ${ }^{13}$ American Memorial Hospital, Reims, France; ${ }^{14}$ Hôpital Jean Bernard, Poitiers, France; ${ }^{15}$ Centre Hospitalier Dupuytren, Limoges, France; ${ }^{16}$ Centre Hospitalier A Morvan, Brest, France; ${ }^{17}$ Centre Robert Debré, Angers, France; ${ }^{18}$ Centre Hospitalier Universitaire, Amiens, France

The objective of the present study was to investigate the role of early common infections and perinatal characteristics in the aetiology of childhood common leukaemia. A case-control study was conducted from 1995 to 1998 in France, and included 473 incident cases of acute leukaemia (AL) (408 acute lymphoblastic leukaemia (ALL), 65 acute myeloid leukaemia (AML) age-, sex- and regionmatched with 567 population-based controls. Data on the medical history of the child and his/her environment were collected using self-administered questionnaires. Analyses were conducted using nonconditional logistic regression. A slight negative association with early infections was observed $(\mathrm{OR}=0.8 ; 95 \% \mathrm{Cl}(0.6-1.0))$. The association was stronger for early gastrointestinal infections. Early day-care was found to be associated with a decreased risk of $A L(O R=0.6 ; 95 \% \mathrm{Cl}(0.4-0.8)$ and $O R=0.8 ; 95 \% \mathrm{Cl}(0.5-1.2)$ for day-care starting before age 3 months and between 3 and 6 months, respectively). No association with breast-feeding was observed, irrespective of its duration. A birth order of 4 or more was associated with a significantly increased risk of $A L(O R=2.0 ; 95 \% \mathrm{Cl}$ $(\mathrm{I} . \mathrm{I}$-3.7) with ALL). A history of asthma was associated with a decreased risk of $\mathrm{ALL}(\mathrm{OR} 0.5 ; 95 \% \mathrm{Cl}(0.3-0.90)$. Although the results regarding birth order and breast-feeding do not fit with Greaves' hypothesis, the study supports the hypothesis that early common infections may play a protective role in the aetiology of childhood leukaemia, although this effect was not more marked for common ALL.

British Journal of Cancer (2004) 90, I39- |45. doi:I0.1038/sj.bjc.660I384 www.bjcancer.com

(C) 2004 Cancer Research UK

Keywords: childhood; leukaemia; infections; perinatal; epidemiology

Childhood leukaemia is the most common cancer of childhood and only a few cases can be explained by known risk factors, such as ionising radiation, cancer chemotherapy or Down's syndrome.

Greaves has formulated the hypothesis that delayed exposure to common infections leads to an increased risk of childhood leukaemia, especially common pre-B acute lymphoblastic leukaemia (ALL), which has an incidence peak between ages 2 and 6 years. Childhood ALL is considered to be a rare response to common infections (Greaves, 1988; Greaves and Alexander, 1993; Greaves, 1997). The pathogenesis of leukaemia is believed to occur in two phases. The first genetic event is considered to take place during pregnancy, during the expansion of B-cell precursors. The second genetic event is thought to occur in the same mutant clone, following an immune stress, such as a common infection. The delayed exposure to infection is considered to increase the number of target cells with the 'first hit' present at older ages. On the basis of this hypothesis, a child isolated from infectious agents at the

*Correspondence: Dr J Clavel; E-mail: clavel@vjf.inserm.fr Received 21 February 2003; revised 8 September 2003; accepted 12 September 2003 beginning of his/her life would be at a higher risk of ALL, while a high birth order value, early common infections and early day-care would be protective factors.

The present study investigated Greaves' hypothesis in a population-based case-control study by analysing the relations between childhood acute leukaemia (AL) and early common infections, day-care attendance and breast-feeding, paying particular attention to ALL. Perinatal characteristics and childhood medical history were also investigated.

\section{SUBJECTS AND METHODS}

\section{Subjects}

A population-based case-control study was conducted from 1995 to 1998. Cases were derived from the National Registry of Childhood Leukaemia and Lymphoma (NRCL), which registers all the cases of leukaemia among children less than 15 in mainland France since 1990. Thus, to be eligible in the study, cases were required to be under 15 years old and be a resident in mainland France at the time of diagnosis. In addition, the mother had to be 
able to fill out a questionnaire and the doctor had to authorise contact with the mother. Cases in four regions that were already involved in a hospital-based case-control study (Perrillat et al, $2002 a, b)$, and the cases in four other regions in which the oncology department could not contribute to the study for practical reasons were excluded.

During the period 1995-1998, the NRCL registered 786 cases of $\mathrm{AL}$ in the 14 regions. Of those cases, 646 were eligible and 140 were not eligible: 25 were not known at the time of the study, two were known not to have parents, three had parents who were unable to fill out the questionnaire for linguistic (1) or social (2) reasons, 110 were too sick for their parents to be interviewed ( 28 of them died before the physician could pass on the questionnaire). The serious condition of the cases was a particular reason for noneligibility before the age of 1 year, when 17 out of the 33 registered cases were eligible. The overall participation rate, relative to all registered cases, was thus $60.2 \%$ (473 out of 786), and the response rate was $73.2 \%$ (473 out of 646 ).

The controls were randomly selected from the general population with stratification respecting the age, gender and regional distribution of the cases. Both the case and control mothers completed a self-administered questionnaire, distributed by the child's physician for cases, and by mail for controls. Controls were randomly selected using age, sex and region quotas from a sample of 30000 phone numbers representative of the French population with respect to area of residence and municipality size categories. The control distribution was determined a priori, on the basis of the expected age, sex and region distribution of the cases derived from the previous years of registration. The study was designed with the same number of cases as controls with a frequency matching on age, sex and region.

A total of 805 controls were eligible. The mothers of 574 controls completed the self-administered questionnaire. Five controls were excluded because they were adopted and two because the questionnaires had too many missing values (only the first page, i.e. circumstances of birth, was completed). Thus, a total of 567 controls were included in the study. The response rate was $71 \%$ for the controls.

\section{Data collection}

On average, the questionnaire was completed 10 months after the diagnosis (before 6 months for 212 cases, between 6 and 12 months for 113 cases, between 12 and 18 months for 76 cases, after 18 months for 72 cases). It was completed within 6 months for the controls.

Details on the diagnosis of leukaemia were collected from the medical records by the Registry investigators. Data on the perinatal period, child's medical history and environment were collected using a standardised self-administered questionnaire. The questions on medical history were closed questions. The data on early infections included the history of ear, nose or throat (ENT), gastrointestinal (GI) and other infections, and the frequency of each type of infection $(\geqslant 1$ per month; $<1$ per month and $\geqslant 1$ per quarter; $<1$ per quarter and $\geqslant 1$ per year, less often) for the age groups: $<1 ; 1-2 ; 3-4 ; 5$ years and more.

The data on factors promoting infections included birth order of the index child, duration of breast-feeding, and history of day-care attendance.

\section{Statistical analysis}

Odds ratios (OR) were estimated using an unconditional logistic regression model including stratification variables, that is, gender, age and region, using the SAS ${ }^{\mathbb{R}}$ software package.

The analyses of day-care attendance, early infections and breastfeeding were restricted to children aged over 1 year in order to be certain that infections before age 1 had already taken place in both the cases and the controls.

The children with Down's syndrome (10 cases and two controls) were excluded from most of the analyses.

\section{RESULTS}

The cases and controls were very similar with respect to age, gender and region of residence at the time of diagnosis (Table 1). In total, $48 \%$ of the cases and $45 \%$ of the controls contributed to the age groups $2-3$ and $4-5$ years, corresponding to the peak of incidence of leukaemia, and 12 cases (3\%) and 35 controls (6\%) were younger than 1 year.

There was no difference between the cases and controls with respect to the distribution of parental socioprofessional category, or maternal or paternal educational level.

Table I Sample description for the cases and controls

\begin{tabular}{|c|c|c|c|}
\hline & $\begin{array}{l}\text { Cases (\%) } \\
(N=473)\end{array}$ & $\begin{array}{c}\text { Controls (\%) } \\
(N=567)\end{array}$ & $P$ \\
\hline \multicolumn{3}{|l|}{ Gender } & NS \\
\hline Male & $260(55)$ & $326(57)$ & \\
\hline \multicolumn{3}{|l|}{ Age at diagnosis (years) } & NS \\
\hline $0-1$ & $45(10)$ & & \\
\hline $2-3$ & $115(24)$ & $78(14)$ & \\
\hline $4-5$ & $110(23)$ & $148(26)$ & \\
\hline $6-9$ & $113(24)$ & $109(19)$ & \\
\hline \multirow[t]{2}{*}{$10-15$} & $90(19)$ & $130(23)$ & \\
\hline & & $102(18)$ & \\
\hline \multicolumn{3}{|l|}{ Region of residence at diagnosis } & NS \\
\hline Alsace & $28(6)$ & $29 \quad(5)$ & \\
\hline Aquitaine & $59(12)$ & $42(7)$ & \\
\hline Bretagne & $45(10)$ & $70(12)$ & \\
\hline Centre & $51(11)$ & $62(11)$ & \\
\hline Champagne Ardennes & $22(5)$ & $33(6)$ & \\
\hline Franche-Comté & $28(6)$ & $31 \quad(5)$ & \\
\hline Languedoc-Roussillon & $31 \quad(7)$ & 48 (8) & \\
\hline Limousin & $8(2)$ & 14 (2) & \\
\hline Midi-Pyrénées & $33(7)$ & $42(7)$ & \\
\hline Basse-Normandie & $29(6)$ & $28 \quad(5)$ & \\
\hline Haute-Normandie & $29(6)$ & $27 \quad(5)$ & \\
\hline Pays de Loire & $48(10)$ & $75(13)$ & \\
\hline Picardie & $31(7)$ & $36(6)$ & \\
\hline Poitou-Charentes & $31 \quad(7)$ & 30 (5) & \\
\hline \multicolumn{3}{|l|}{ Socioprofessional categories } & \\
\hline Without employment & $15 \quad(3)$ & $8(1)$ & \\
\hline Craftsmen and factory workers & $132(28)$ & $118(21)$ & \\
\hline Farmers and agricultural workers & 14 (3) & $29(5)$ & \\
\hline Sales and service workers & $49(10)$ & $80(14)$ & \\
\hline Administrative employees & $66(14)$ & $105(19)$ & \\
\hline Intermediate profession & $95(20)$ & $104(19)$ & \\
\hline Intellectual and scientific jobs & $55(12)$ & $64(11)$ & \\
\hline Managers & $43(9)$ & $54(10)$ & \\
\hline$x^{a}$ & 4 & 5 & \\
\hline \multicolumn{3}{|l|}{ Maternal education } & NS \\
\hline$<$ high school & $337(74)$ & $415(74)$ & \\
\hline$>$ high school & $120(26)$ & $144(26)$ & \\
\hline$x^{a}$ & 16 & 8 & \\
\hline \multicolumn{3}{|l|}{ Patemal education } & NS \\
\hline < high school & $337(77)$ & $424(79)$ & \\
\hline > high school & $102(23)$ & $113(21)$ & \\
\hline$x^{a}$ & 34 & 30 & \\
\hline
\end{tabular}

aMissing values. 
Table 2 Perinatal characteristics and childhood leukaemia

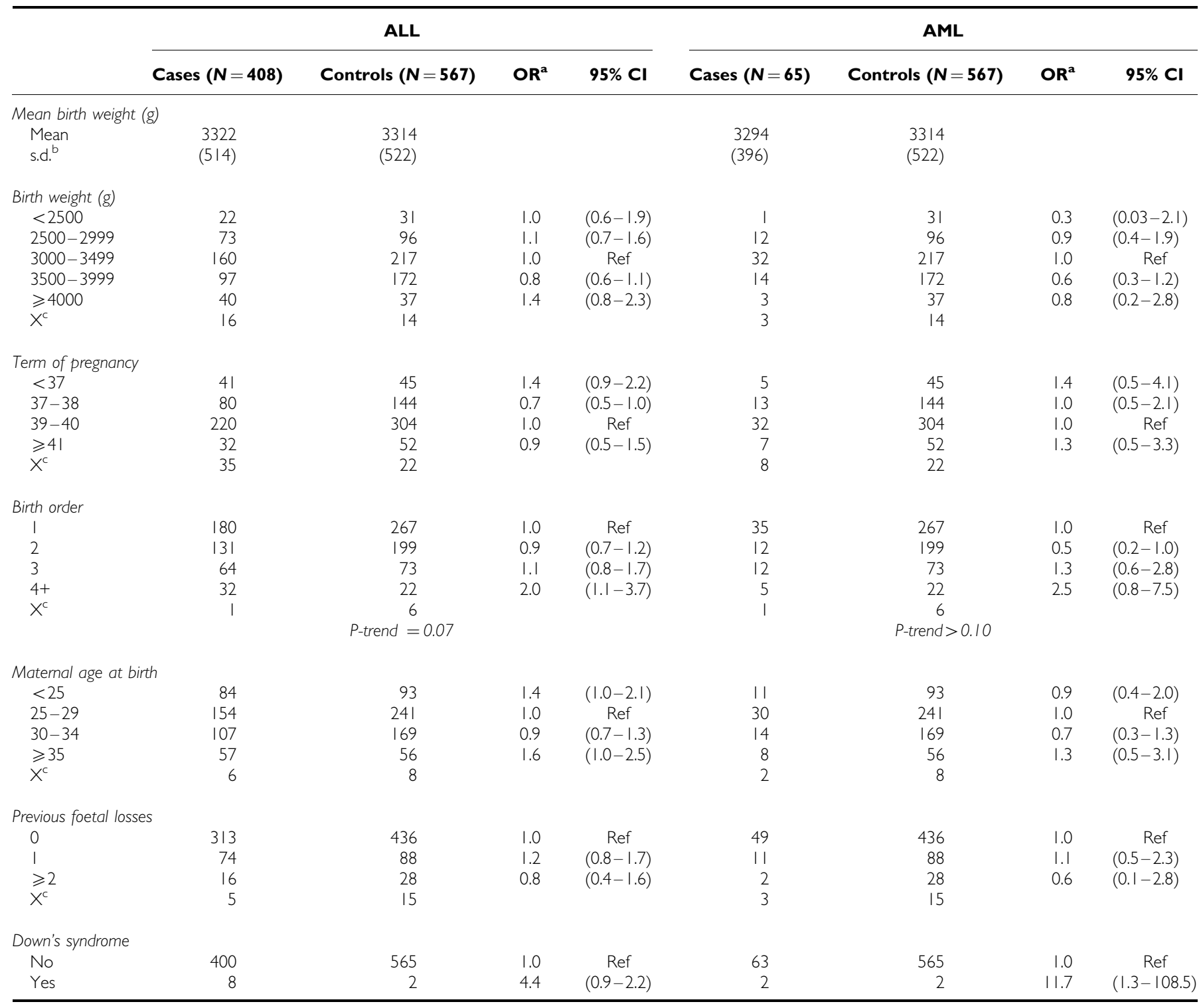

${ }^{a}$ Adjusted for stratification variables (gender, age at diagnosis, region of residence at diagnosis). ${ }^{b}$ s.d. $=$ standard deviation. ${ }^{c} X=$ missing values.

No association between childhood leukaemia and birth weight, term of pregnancy, maternal age at birth and history of previous foetal losses was observed (Table 2).

A statistically significant association between birth order and childhood ALL was observed ( $P$-trend $=0.07-\mathrm{OR}=2.0 ; \mathrm{CI}$ (3.1-3.7) for children born fourth). A similar association was observed with AML.

No association between breast-feeding, irrespective of its duration, and childhood AL was observed (Table 3).

The results for early infections are shown in Table 4 . The mothers of 122 cases (104 ALL and 18 AML) and of 172 controls declared at least four common infections in the first year of their child's life. ENT infections were highly predominant, while infections other than ENT were reported at lower frequency: 44 cases and 52 controls reported only one GI infection during the first year and 15 cases and 26 controls reported only one infection other than ENT or GI during the first year. A statistically significant negative association between common infections before age 1 year and childhood ALL $(\mathrm{OR}=0.8$; CI $(0.6-1.0))$ was observed. This association was not observed with AML. The association was stronger for early GI infections $(\mathrm{OR}=0.1$; CI $(0.03-0.6))$, but this finding was based on only two cases and 18 controls.

In order to evaluate the potential influence of the missing values on the results presented in Table 4, we also estimated the OR associated with total ENT or GI infections either by including the missing values for cases and controls in the category of the least infected children or by including the missing values of cases and controls in the category of the most frequently infected children. The OR remained significantly less than 1 if missing values were assigned to the unexposed group, and increased at most to 1.0 if, conversely, the missing values were assigned to the group of children who had more than four infections in their first year of life.

Taken as a whole, day-care attendance was associated with childhood AL (OR $=0.7$; CI $(0.6-1.0)$ for ALL) as shown in Table 5. The association was only observed when day-care started before age 6 months $(\mathrm{OR}=0.6$; $\mathrm{CI}(0.4-0.8)$ for age less than 3 months; 
Table 3 Association between childhood acute leukaemia and breast-feeding (analysis restricted to children older than I year)

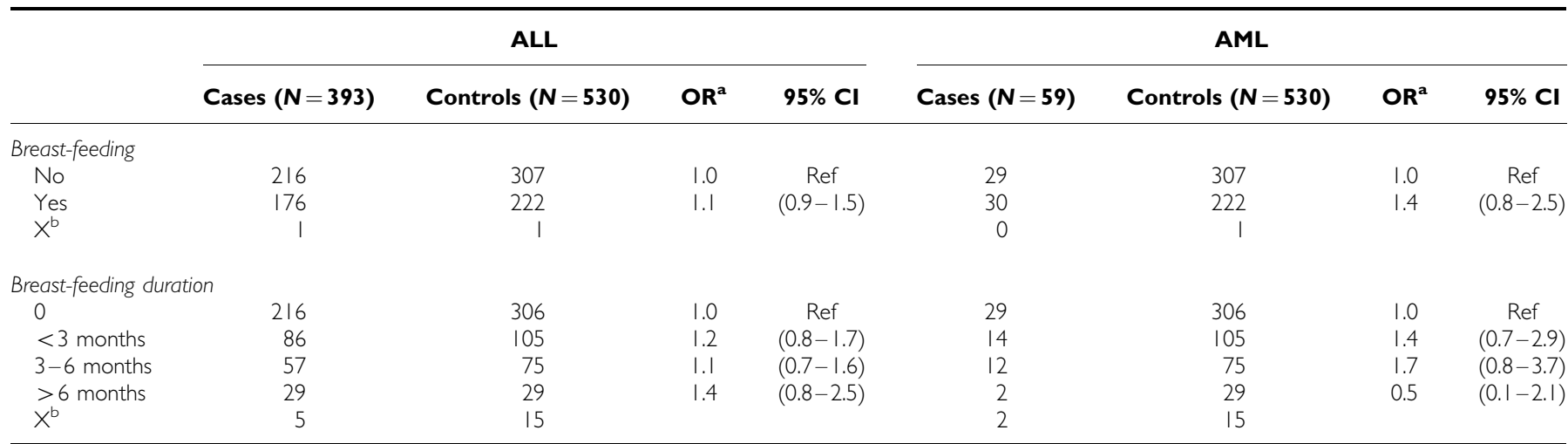

${ }^{a}$ ORs adjusted for stratification variables: gender, age at diagnosis, region of residence at diagnosis. ${ }^{b} \mathrm{X}=$ missing values.

Table 4 Association between childhood acute leukaemia and common early infections (analysis restricted to children older than I year)

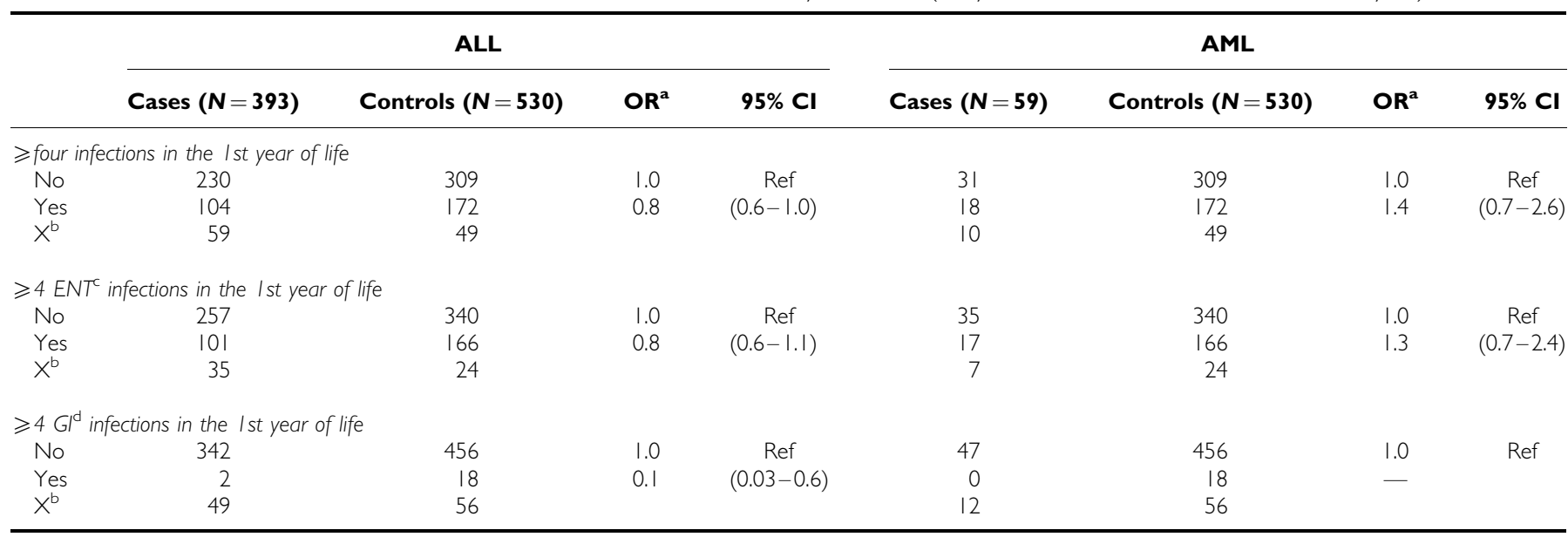

${ }^{a}$ ORs adjusted for stratification variables: gender, age at diagnosis, region of residence at diagnosis. ${ }^{b} \mathrm{X}=$ missing values. ${ }^{\mathrm{C}} \mathrm{ENT}=$ ear, nose throat. ${ }^{\mathrm{d}} \mathrm{Gl}=$ gastrointestinal.

$\mathrm{OR}=0.8 ; \mathrm{CI}(0.5-1.2)$ for age $3-6$ months $)$. The trend with respect to the age of starting day-care was statistically significant.

After exclusion of children with Down's syndrome, 221 cases (210 ALL and $11 \mathrm{AML}$ ) and 255 controls belonged to the $2-6$ years age bracket corresponding to the incidence peak, while 199 cases (161 ALL and $38 \mathrm{AML}$ ) and 232 controls were 6 years old or more. Of the 393 ALL after age one, 304 were of the common B-cell type, 54 were of the T-cell type, and four were B mature.

Data were also analysed separately depending on the age at diagnosis (2-6 years $v s$ older) and on the subtype of ALL (common B-cell $v s$ other ALL). The association between early frequent common infections and $\mathrm{AL}$ was restricted to the 2-6 years age group, but not to the common B-cell ALL subtype (Table 6). The associations with day-care were specific neither to the common B cell ALL subtype nor to the age bracket 2-6 years.

As shown in Table 7, a statistically significant negative association between asthma and childhood ALL was observed $(\mathrm{OR}=0.5$; CI $(0.3-0.9))$. The association was even stronger for asthmatic children regularly treated with bronchodilators $(\mathrm{OR}=0.3$; CI $(0.1-0.7))$.

No significant association with a history of chickenpox, mumps or glandular fever was observed (Table 7). In contrast, ALL was associated with a history of measles $(\mathrm{OR}=1.7$; $\mathrm{CI}(1.0-2.9))$ and rubella $(\mathrm{OR}=2.4$; $\mathrm{CI}(1.4-4.1))$. A history of viral hepatitis was only reported for two cases and one control $(\mathrm{OR}=3.3$; CI $(0.3-$ $37.0)$ ).

\section{DISCUSSION}

One of the main objectives of the present population-based study was to test whether early common infections were associated with a reduced risk of AL. Slight negative associations between ALL and common early infections and day-care were observed. No association with breast-feeding, irrespective of duration, was observed. A birth order of four or more was associated with an increased risk of AL. A history of two or more infantile viral diseases was positively associated with ALL while a history of asthma was negatively associated with ALL.

The data were collected from a standardised self-administered questionnaire. The response rates for the cases and controls were very similar and the nonrespondent controls did not differ from the respondent controls in terms of age, gender or region of residence. The percentage mortality rates, obtained from the NRCL, for the respondent and nonrespondent cases were very similar (12 and $8 \%$, respectively) making a strong survival bias unlikely. The exhaustiveness of the NRCL is close to $99 \%$, making unlikely a selection through the process of cases' identification.

Recalling common infections may be difficult, and this may explain the rather high number of missing values in the questionnaires. However, when the missing values were assigned either exposed or unexposed status (with the hypothesis of a nondifferential bias), the OR remained less than unity. An OR of 1.0 was only obtained when all the missing values were classed as 
Table 5 Association between childhood acute leukaemia and day-care attendance (analysis restricted to children older than I year)

\begin{tabular}{|c|c|c|c|c|c|c|c|c|}
\hline & \multicolumn{4}{|c|}{ ALL } & \multicolumn{4}{|c|}{ AML } \\
\hline \multicolumn{9}{|l|}{ Day-care } \\
\hline No & 220 & 259 & 1.0 & Ref & 34 & 259 & 1.0 & Ref \\
\hline Yes & 167 & 266 & 0.7 & $(0.6-1.0)$ & 24 & 266 & 0.8 & $(0.5-1.5)$ \\
\hline$x^{b}$ & 6 & 5 & & & । & 5 & & \\
\hline \multicolumn{9}{|l|}{ Type of day-care } \\
\hline Nurse only & 120 & 198 & 0.7 & $(0.5-1.0)$ & 17 & 198 & 0.8 & $(0.4-1.6)$ \\
\hline Full time day-care centre only & 29 & 34 & I.1 & $(0.6-1.8)$ & 5 & 34 & 1.3 & $(0.4-3.7)$ \\
\hline Occasional day-care centre only & 6 & 15 & 0.4 & $(0.2-1.2)$ & । & 15 & 0.7 & $(0.1-6.4)$ \\
\hline More than one type of day-care & 12 & 19 & 0.7 & $(0.3-1.5)$ & I & 19 & 0.6 & $(0.1-5.1)$ \\
\hline$x^{b}$ & 6 & 5 & & & i & 5 & & \\
\hline \multicolumn{9}{|c|}{ Age at start of day-care (nurse or day-care centre) } \\
\hline \multirow[t]{2}{*}{$x^{b}$} & 13 & 19 & & & 2 & 19 & & \\
\hline & & & $P$-trend $<0.05$ & & & & & \\
\hline \multicolumn{9}{|l|}{ Age at start of full-time day-care centre } \\
\hline Never & 348 & 475 & 1.0 & Ref & 52 & 475 & 1.0 & Ref \\
\hline $1-3$ months & 10 & 23 & 0.6 & $(0.3-1.3)$ & 3 & 23 & 1.5 & $(0.4-5.6)$ \\
\hline $4-6$ months & 9 & 10 & 1.4 & $(0.5-3.5)$ & 3 & 10 & 2.5 & $(0.6-10.2)$ \\
\hline $7-12$ months & 8 & 6 & 2.1 & $(0.7-6.2)$ & 0 & 6 & & \\
\hline$\geqslant 12$ months & 11 & 9 & 1.6 & $(0.6-4.0)$ & 0 & 9 & & \\
\hline$x^{b}$ & 7 & 7 & & & । & 7 & & \\
\hline
\end{tabular}

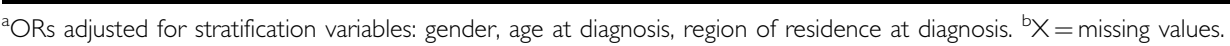

Table 6 Association between childhood acute leukaemia and factors implicated in Greaves' hypothesis, according to age at diagnosis and ALL subtype

\begin{tabular}{|c|c|c|c|c|c|c|c|c|}
\hline & \multicolumn{4}{|c|}{ Age } & \multicolumn{4}{|c|}{ ALL subtype ${ }^{a}$} \\
\hline & $O R^{b}$ & $95 \% \mathrm{Cl}$ & $O R^{b}$ & $95 \% \mathrm{Cl}$ & $O R^{b}$ & $95 \% \mathrm{Cl}$ & $O_{R^{b}}$ & $95 \% \mathrm{Cl}$ \\
\hline \multicolumn{9}{|c|}{$\geqslant 4$ infections in the Ist year of life } \\
\hline Any infection & 0.7 & $(0.5-1.0)$ & 1.0 & $(0.6-1.6)$ & 0.8 & $(0.6-1.1)$ & 0.7 & $(0.4-1.1)$ \\
\hline ENT & 0.7 & $(0.5-1.0)$ & 1.0 & $(0.6-1.6)$ & 0.8 & $(0.6-1.1)$ & 0.7 & $(0.4-1.2)$ \\
\hline Yes vs no & 0.8 & $(0.5-1.2)$ & 0.7 & $(0.5-1.1)$ & 0.8 & $(0.6-1.0)$ & 0.5 & $(0.3-0.9)$ \\
\hline \multicolumn{9}{|c|}{ Age at start of day-care (any type) } \\
\hline$<3$ months & 0.6 & $(0.4-1.0)$ & 0.7 & $(0.4-1.2)$ & 0.6 & $(0.4-0.9)$ & 0.4 & $(0.2-0.8)$ \\
\hline $3-6$ months & 0.9 & $(0.5-1.6)$ & 0.8 & $(0.4-1.3)$ & 0.8 & $(0.6-1.3)$ & 0.5 & $(0.2-1.1)$ \\
\hline$>6$ months & 1.3 & $(0.7-2.4)$ & 0.7 & $(0.4-1.6)$ & I.1 & $(0.7-1.8)$ & 1.0 & $(0.5-2.1)$ \\
\hline Never & 1.0 & Ref & 1.0 & Ref & 1.0 & Ref & 1.0 & Ref \\
\hline$\geqslant 4$ & 1.5 & $(0.7-3.3)$ & 2.4 & $(0.9-6.3)$ & 2.0 & $(1.1-3.8)$ & 2.3 & $(0.9-6.1)$ \\
\hline \multicolumn{9}{|l|}{ Breast-feeding } \\
\hline Yes vs no & 1.0 & $(0.7-1.5)$ & 1.4 & $(0.9-2.0)$ & 1.2 & $(0.9-1.5)$ & 1.1 & $(0.7-1.8)$ \\
\hline \multicolumn{9}{|c|}{ Breast-feeding duration } \\
\hline Never & 1.0 & Ref & 1.0 & Ref & 1.0 & Ref & 1.0 & Ref \\
\hline$<3$ months & 0.8 & $(0.5-1.3)$ & 1.7 & $(1.0-2.9)$ & 1.2 & $(0.8-1.7)$ & I.I & $(0.6-1.9)$ \\
\hline$\geqslant 3$ months & 1.4 & $(0.8-2.2)$ & 1.0 & $(0.6-1.6)$ & 1.2 & $(0.8-1.7)$ & 1.3 & $(0.7-2.2)$ \\
\hline
\end{tabular}

${ }^{a}$ Analysis restricted to children older than I year. ${ }^{b}$ ORs adjusted for stratification variables: gender, age at diagnosis, region of residence at diagnosis. 
Table 7 Medical history of asthma or infantile diseases and risk of childhood acute leukaemia

\begin{tabular}{|c|c|c|c|c|c|c|c|c|}
\hline & \multicolumn{4}{|c|}{ ALL } & \multicolumn{4}{|c|}{ AML } \\
\hline Asthma & 17 & 44 & 0.5 & $(0.3-0.9)$ & 2 & 44 & 0.4 & $(0.1-1.7)$ \\
\hline \multicolumn{9}{|c|}{ Asthma and/or bronchodilators (BD) } \\
\hline No asthma and no BD & 358 & 501 & 1.0 & Ref & 59 & 501 & 1.0 & Ref \\
\hline Asthma or BD & 25 & 31 & 1.0 & $(0.6-1.8)$ & 2 & 31 & 0.7 & $(0.1-3.0)$ \\
\hline \multicolumn{9}{|c|}{ Infantile diseases before the diagnosis } \\
\hline Measles & 41 & 38 & 1.7 & $(1.0-2.9)$ & 8 & 38 & 1.3 & $(0.5-3.1)$ \\
\hline Rubella & 37 & 24 & 2.4 & $(1.4-4.1)$ & 3 & 24 & 1.1 & $(0.3-3.9)$ \\
\hline Mumps & 24 & 20 & 1.9 & $(1.0-3.6)$ & 6 & 20 & 1.6 & $(0.6-4.5$ \\
\hline Chickenpox & 220 & 323 & 0.9 & $(0.6-1.2)$ & 33 & 323 & 0.7 & $(0.3-1.4)$ \\
\hline \multicolumn{9}{|c|}{ Any of the above infantile diseases } \\
\hline
\end{tabular}

${ }^{a}$ ORs adjusted for stratification variables: gender, age at diagnosis, region of residence at diagnosis. ${ }^{b} \mathrm{X}=$ missing values.

'most often infected', which is very unlikely. Case mothers may have declared minor health problems less often, and thus introduced a differential recall bias. However, the self-administered questionnaire contained closed and very precise questions. Over-reporting by control mothers was possible, but unlikely. Conversely, a nondifferential recall bias was more likely, given that the questionnaire was self-administered, and may have reduced the association with common early infections.

Few papers have addressed the role of early common infections yet. All but one (Dockerty et al, 1999) found a negative association with early common infections. Van Steensel-Moll et al (1986) observed a significant negative association between common colds before age 1 year and the risk of ALL. Neglia et al (2000) observed a significant trend towards a reduction in the risk of AL with an increase in the number of episodes of otitis before age 1 year. The trend was stronger for ALL. Perrillat et al (2002b) found a negative association between the risk of ALL and a history of four or more episodes of otitis before age 2 years, on the one hand, and a history of ENT surgical procedures before age 2 years, on the other hand.

Day-care attendance can be considered a surrogate of early contact with infections. In our study, day-care was slightly negatively associated with ALL when initiated early. However, curiously, the association did not concern full-time day-care centres. All the authors who have studied the association between day-care and leukaemia have reported OR of less than one (Petridou et al, 1993, 1997; Neglia et al, 2000). However, only four studies found significant negative associations (Infante-Rivard et al, 2000; Rosenbaum et al, 2000; Ma et al, 2002; Perrillat et al, $2002 \mathrm{~b})$. When age at the start of day-care was studied, the negative association was stronger for the youngest.

With regard to breast-feeding, recall bias is difficult to imagine since the mother was asked to indicate the duration of breastfeeding. The questionnaire did not distinguish between mixed feeding and complete breast-feeding. Over-reporting of longduration breast-feeding by case mothers cannot be ruled out since some mothers may experience feelings of guilt with regard to breast-feeding. However, such a recall bias is likely to concern mothers who only breastfed for a short duration rather than those who did not breast-feed at all, and is probably insufficient to explain the absence of a negative association. Confounding by birth order is possible, since the older children were less often breastfed and received breast-feeding for shorter durations than the controls. However, adjustments for birth order did not modify the association and there was no interaction between the two variables. The majority of the studies investigating breast-feeding have found a negative association with childhood AL (Davis et al, 1988; Petridou et al, 1997; Infante-Rivard et al, 2000; Rosenbaum et al, 2000), which was more marked for prolonged breast-feeding (Magnani et al, 1988; Dockerty et al, 1999; Shu et al, 1999; Smulevich et al, 1999; Bener et al, 2001; Hardell and Dreifaldt, 2001; Perrillat et al, 2002a).

The positive association with birth order observed in the present study was unexpected and did not seem to be explained by sociodemographic characteristics or by the other variables under study. Control mothers with the largest families may have been counter-selected, for instance, because they would have been less available to answer the questionnaire. Although first-born status was included in Greaves' hypothesis as a risk factor, many studies have not observed any association between birth order and ALL or AL (Kaye et al, 1991; Petridou et al, 1993, 1997; Roman et al, 1997; Westergaard et al, 1997; McKinney et al, 1999; Shu et al, 1999; Neglia et al, 2000). Only three authors have observed a significant negative association between the risk of leukaemia (or ALL) and birth order (Van Steensel-Moll et al, 1986; Schuz et al, 1999a; Dockerty et al, 2001), in line with Greaves' hypothesis. In contrast, three studies have found a significant positive association between the risk of AL and birth order (Savitz and Ananth, 1994; InfanteRivard et al, 2000; Shu et al, 2002).

The negative relation with asthma and bronchodilators may be fortuitous. However, several authors have already pointed out the possibility of a negative association with asthma and other allergic diseases (Magnani et al, 1990; Petridou et al, 1997; Schuz et al, 1999b; Wen et al, 2000), and the association deserves further investigation.

In conclusion, although the results regarding birth order and breast-feeding do not fit with Greaves' hypothesis, the study supports the hypothesis that early common infections may play a protective role in the aetiology of childhood leukaemia, although this effect was not more marked for common ALL.

\section{ACKNOWLEDGEMENTS}

We are grateful to Sabine Mélèze (Institut Démoscopie), who coordinated the random selection of the controls, to Martine Valdes and Dominique Ridondelli (Inserm U170) for technical 
assistance, and to Andrew Mullarky for his skillful revision of the manuscript. This work was supported by grants from Inserm, the Ministère de l'Environnement et de l'Aménagement du Territoire, the Fondation pour la Recherche Médicale, the Association pour la Recherche contre le Cancer, the Fondation de France and the Institut Electricité Santé.

\section{REFERENCES}

Bener A, Denic S, Galadari S (2001) Longer breast-feeding and protection against childhood leukaemia and lymphomas. Eur J Cancer 37(2): $234-238$

Davis MK, Savitz DA, Graubard BI (1988) Infant feeding and childhood cancer. Lancet 2(8607): $365-368$

Dockerty JD, Skegg DC, Elwood JM, Herbison GP, Becroft DM, Lewis ME (1999) Infections, vaccinations, and the risk of childhood leukaemia. $\mathrm{Br} J$ Cancer 80(9): $1483-1489$

Dockerty JD, Draper G, Vincent T, Rowan SD, Bunch KJ (2001) Casecontrol study of parental age, parity and socioeconomic level in relation to childhood cancers. Int J Epidemiol 30(6): 1428-1437

Greaves MF (1988) Speculations on the cause of childhood acute lymphoblastic leukemia. Leukemia 2(2): $120-125$

Greaves MF, Alexander FE (1993) An infectious etiology for common acute lymphoblastic leukemia in childhood? Leukemia 7(3): 349-360

Greaves MF (1997) Aetiology of acute leukaemia. Lancet 349(9048): $344-349$

Hardell L, Dreifaldt AC (2001) Breast-feeding duration and the risk of malignant diseases in childhood in Sweden. Eur J Clin Nutr 55(3): $179-185$

Infante-Rivard C, Fortier I, Olson E (2000) Markers of infection, breastfeeding and childhood acute lymphoblastic leukaemia. Br J Cancer 83(11): 1559-1564

Kaye SA, Robison LL, Smithson WA, Gunderson P, King FL, Neglia JP (1991) Maternal reproductive history and birth characteristics in childhood acute lymphoblastic leukemia. Cancer 68(6): 1351-1355

Ma X, Buffler PA, Selvin S, Matthay KK, Wiencke JK, Wiemels JL, Reynolds P (2002) Daycare attendance and risk of childhood acute lymphoblastic leukaemia. Br J Cancer 86(9): 1419-1424

Magnani C, Pastore G, Terracini B (1988) Infant feeding and childhood cancer. Lancet 2(8620): 1136

Magnani C, Pastore G, Luzzatto L, Terracini B (1990) Parental occupation and other environmental factors in the etiology of leukemias and nonHodgkin's lymphomas in childhood: a case - control study. Tumori 76(5): $413-419$

McKinney PA, Juszczak E, Findlay E, Smith K, Thomson CS (1999) Pre- and perinatal risk factors for childhood leukaemia and other malignancies: a Scottish case control study. Br J Cancer 80(11): 1844-1851

Neglia JP, Linet MS, Shu XO, Severson RK, Potter JD, Mertens AC, Wen W, Kersey JH, Robison LL (2000) Patterns of infection and day care utilization and risk of childhood acute lymphoblastic leukaemia. $\mathrm{Br} \mathrm{J}$ Cancer 82(1): 234-240

Perrillat F, Clavel J, Jaussent I, Baruchel A, Leverger G, Nelken B, Philippe N, Schaison G, Sommelet D, Vilmer E, Hemon D (2002a) Breastfeeding, fetal loss and childhood acute leukaemia. Eur J Pediatr 161(4): $235-237$
Perrillat F, Clavel J, Auclerc MF, Baruchel A, Leverger G, Nelken B, Philippe N, Schaison G, Sommelet D, Vilmer E, Hemon D (2002b) Day-care, early common infections and childhood acute leukaemia: a multicentre French case-control study. Br J Cancer 86(7): 1064-1069

Petridou E, Kassimos D, Kalmanti M, Kosmidis H, Haidas S, Flytzani V, Tong D, Trichopoulos D (1993) Age of exposure to infections and risk of childhood leukaemia. BMJ 307(6907): 774

Petridou E, Trichopoulos D, Kalapothaki V, Pourtsidis A, Kogevinas M, Kalmanti M, Koliouskas D, Kosmidis H, Panagiotou JP, Piperopoulou F, Tzortzatou F (1997) The risk profile of childhood leukaemia in Greece: a nationwide case-control study. Br J Cancer 76(9): 1241 - 1247

Roman E, Ansell P, Bull D 1997 Leukaemia and non-Hodgkin's lymphoma in children and young adults: are prenatal and neonatal factors important determinants of disease? Br J Cancer 76(3): 406-415

Rosenbaum PF, Buck GM, Brecher ML (2000) Early child-care and preschool experiences and the risk of childhood acute lymphoblastic leukemia. Am J Epidemiol 152(12): 1136- 1144

Savitz DA, Ananth CV (1994) Birth characteristics of childhood cancer cases, controls, and their siblings. Pediatr Hematol Oncol 11(6): 587-599

Schuz J, Kaatsch P, Kaletsch U, Meinert R, Michaelis J (1999a) Association of childhood cancer with factors related to pregnancy and birth. Int $J$ Epidemiol 28(4): 631-639

Schuz J, Kaletsch U, Meinert R, Kaatsch P, Michaelis J (1999b) Association of childhood leukaemia with factors related to the immune system. $\mathrm{Br} J$ Cancer 80(3-4): $585-590$

Shu XO, Linet MS, Steinbuch M, Wen WQ, Buckley JD, Neglia JP, Potter JD, Reaman GH, Robison LL (1999) Breast-feeding and risk of childhood acute leukemia. J Natl Cancer Inst 91(20): 1765-1772

Shu XO, Han D, Severson RK, Chen Z, Neglia JP, Reaman GH, Buckley JD, Robison LL (2002) Birth characteristics, maternal reproductive history, hormone use during pregnancy, and risk of childhood acute lymphocytic leukemia by immunophenotype (United States). Cancer Causes Control 13(1): $15-25$

Smulevich VB, Solionova LG, Belyakova SV (1999) Parental occupation and other factors and cancer risk in children: I. Study methodology and nonoccupational factors. Int J Cancer 83(6): 712-717

Van Steensel-Moll HA, Valkenburg HA, van Zanen GE (1986) Childhood leukemia and infectious diseases in the first year of life: a register-based case - control study. Am J Epidemiol 124(4): 590-594

Wen W, Shu XO, Linet MS, Neglia JP, Potter JD, Trigg ME, Robison LL (2000) Allergic disorders and the risk of childhood acute lymphoblastic leukemia (United States). Cancer Causes Control 11(4): 303-307

Westergaard T, Andersen PK, Pedersen JB, Olsen JH, Frisch M, Sorensen HT, Wohlfahrt J, Melbye M (1997) Birth characteristics, sibling patterns, and acute leukemia risk in childhood: a population-based cohort study. J Natl Cancer Inst 89(13): 939-947 